\title{
CHẤT LƯợNG CUỘC SỐNG NGƯờI BÊNHH SAU GHÉP TIM TẠI BỆNH VIỆN HŨ̉U NGHI VIỆT ĐỨC
}

\author{
Nguyê̂n Xuân Vinh*, Phùng Duy Hồng Sơn*, Nguyê̂n Hũu U'ơcc*
}

\section{TÓM TÁ̀T}

Nghiên cứu mô tả hồi cứu và tiến cứu, có phân tích trên 23 bệnh nhân đã ghép tim từ người cho đa tạng chết não tại Trung tâm Tim mạch và Lồng ngực, bệnh viện Hũu nghị Việt Đức, từ tháng 6 / 2012 đến tháng $4 / 2020$, với nền tảng là bộ câu hỏi SF-36. Điểm trung bình của 4 lĩnh vực sức khỏe thể chất bao gồm hoạt động chức năng, giới hạn chức năng, cảm nhận đau đớn và sức khỏe tổng quát lần lượt là 87,$4 ; 86,6 ; 92,1$ và 80,8 . Điểm trung bình của 4 lĩnh vực sức khỏe tinh thần bao gồm cảm nhận sức sống, hoạt động xã hội, giới hạn tâm lý và tinh thần tổng quát lần lượt là 86,$6 ; 79,2 ; 83,5$ và 86,6 . Các yếu tố có liên quan với chất lượng cuộc sống của bệnh nhân sau ghép tim trong phân tích đa biến là: tuổi, nghề nghiệp, trình độ học vấn, bệnh lý (đái tháo đường, gút, suy thận và xơ gan trước ghép). Điểm số chất lượng cuộc sống của bệnh nhân sau ghép tim tại bệnh viện Hữu nghị Việt Đức đều cao ở tất cả lĩnh vực sức khỏe, chứng minh phẫu thuật ghép tim cho bệnh nhân suy tim giai đoạn cuối là một phương pháp rất hữu ích, giúp cải thiện rõ cuộc sống của người bệnh sau ghép tim.

Tù khóa: Chất lượng cuộc sống, ghép tim, SF-36.

\section{SUMMARY}

\section{HEALTH-RELATED QUALITY OF LIFE OF RECIPIENTS AFTER HEART TRANPLANTATION AT VIET DUC UNIVERSITY HOSPITAL}

Retrospective and prospective descriptive study of consecutive patient after cardiac transplantation patients in 23 cases from June 2012 to April 2020, at the Cardiovascular and Thoracic Center, Viet Duc university hospital, based on SF-36 questionnaire. The mean scores of 4 physical health domains including physical functioning, role physical, bodily pain and general health were $87.4 ; 86.6 ; 92.1$ and 80.8 , respectively. The mean scores of 4 mental health domains including vitality, social functioning, and role emotional and mental health were 86.6; $79.2 ; 83.5$ and 86.6 , respectively. In multivariate analysis, factors associated with HRQOL after cardiac transplantation were age, occupation, education level, some diseases (diabetes mellitus, gout, kidney failure, pre-op cirrhosis). The total points of HRQOL were high in all domains, confirmed that heart transplant surgery for patients with end-stage heart failure is a very useful method, that significantly improving HRQOL recipients after the procedure.

Key words: Health-related quality of life, cardiac transplant, SF-36.

\section{I. ĐẶT VẤN ĐỀ}

Ghép tim là một loại phẫu thuật đặc biệt, để thay thế trái tim bị suy giai đoạn cuối của người bệnh (người nhận) bằng trái tim khỏe mạnh đến từ người hiến chết não phù hợp (người cho chết não), và được coi là phương pháp điều trị triệt để khi mà tất cả các phương pháp điều trị thường qui khác đã thất bại [1]. Lịch sử phát triển của phẫu thuật ghép tim trên người có một khoảng thời gian dài tới 62 năm kể từ khi Alexis Carrel và Charles Guthrie tại Đại học tổng hợp Chicago (Hoa Kỳ) tiến hành ca ghép tim thực nghiệm đầu tiên năm 1902 [2], tới khi Christiaan Barnard ở Cape Town (Nam Phi) thực hiện ca ghép tim đầu tiên trên người ngày 3/12/1967 [3],[4]. Theo báo

*Bệnh viện Hũu nghị Việt Đức

Ngườ chịu trách nhiệm khoa học: Nguyễn Xuân Vinh

Ngày nhận bài: 02/07/2020 - Ngày Cho Phép Đăng: 04/09/2020

Phản Biện Khoa học: PGS.TS. Đặng Ngọc Hùng PGS.TS. Đoàn Quốc Hung 
cáo của tổ chức ghép tim phổi quốc tế, đến tháng $6 / 2017$, ghép tim đã được thực hiện tại 477 trung tâm phẫu thuật tim trên thế giới; với số lượng người bệnh được ghép tim là 141.268 ca. Còn nếu tính từ $1 / 6 / 2016$ đến $30 / 7 / 2017$ đã có 5.149 người bệnh được ghép tim [5].

Tại Việt Nam, phẫu thuật ghép tim đã triển khai thành công từ người cho chết não đơn tạng chết não (chỉ cho tim) tại bệnh viện 103 và Học viện Quân y vào ngày $17 / 6 / 2010$. Ca đầu tiên ghép tim từ người cho đa tạng chết não (cho cả gan, thận, tim ...) được thực hiện tại bệnh viện Việt Đức vào ngày $14 / 4 / 2011$, và sau đó nhanh chóng trở thành một phương pháp điều trị thường qui tại bệnh viện, với số lượng trung bình mỗi năm là 3-5 ca ghép tim kết hợp với 10-15 ca ghép các tạng khác [6].

Về hiệu quả ghép tim, theo báo cáo của tổ chức ghép tim phổi quốc tế năm 2018 , thì tỉ lệ sống thêm 4 năm sau mổ đạt $75 \%$ ở người lớn, sau 10 năm đạt trên $50 \%$, và sau 18 năm đạt $25 \%$ [5]. Ngoài tỉ lệ sống sau ghép tim được cải thiện, sự quan tâm hầu hết tại các quốc gia có ghép tim hiện nay là hướng đến nâng cao chất lượng cuộc sống (CLCS sau ghép) [7]; biến CLCS sau ghép tạng trở thành một tiêu chí đánh giá thành công của phẫu thuật đối với người bệnh được ghép tạng còn sống lâu dài sau ghép [8]. Kết quả dựa trên CLCS bệnh nhân ngày càng được nhấn mạnh khi đánh giá hiệu quả điều trị tổng thể. Các kết quả như vậy bao gồm các biện pháp nâng cao CLCS liên quan đến sức khỏe, là nguồn thông tin có giá trị trong việc xác định liệu bệnh nhân có được điều trị tốt hơn bằng các phương pháp điều trị y tế hay không [9],[10],[11]. Ngày nay, CLCS được xem là công cụ sử dụng phổ biến nhất trong $\mathrm{y}$ học nhằm: (1) lập kế hoạch chăm sóc lâm sàng cho bệnh nhân; (2) làm thước đo kết quả trong các thử nghiệm lâm sàng và nghiên cứu dịch vụ y tế; (3) đánh giá nhu cầu sức khỏe của cộng đồng; (4) hỗ trợ phân bổ nguồn lực hiệu quả. Phần lớn đánh giá
CLCS được ưu tiên áp dụng giải quyết các vấn đề y tế mãn tính và nghiêm trọng. Công cụ SF36 là một phương pháp được sử dụng khá phổ biến đển đánh giá CLCS sau ghép tim [30].

Xuất phát từ tình hình thực tiễn nêu trên, được sự đồng ý của Hội đồng đạo đức bệnh viện Hữu nghị Việt Đức, chúng tôi tiến hành đề tài nghiên cứu "Đánh giá chất lượng cuộc sống người bệnh sau ghép tim từ người cho đa tạng chết não tại bệnh viện Việt Đức bằng công cụ SF36"; với các mục tiêu chính sau đây: (1) Mô tả một số đặc điểm chung của nguời bệnh nhận tim truớc ghép tim tì̀ người cho đa tạng chết não; (2) Đánh giá chất luợng cuộc sống nguời bệnh sau ghép tim tại bệnh viện Hũu nghị Việt Đức bằng công cu SF-36.

\section{II. ĐỐI TƯợng VÀ PHƯơng PHÁP NGHIÊN CÚU}

\section{1. Đối tượng nghiên cứu:}

Bao gồm tất cả những bệnh nhân (người nhận tim) được phẫu thuật ghép tim tại bệnh viện Hữu nghị Việt Đức trong giai đoạn từ tháng 6/2012 đến tháng 10/2019, đạt được các tiêu chuẩn sau:

- Còn sống sau ghép tim $\geq 6$ tháng (thời gian đủ để phục hồi sau phẫu thuật).

- Người bệnh và gia đình đồng ý tham gia nghiên cứu.

- Hồ sơ bệnh án đầy đủ thông tin phục vụ nghiên cứu.

Loại trù khỏi nghiên cứu các đối tượng: hoặc đã chết ở thời điểm thu thập số liệu nghiên cúu, hoạc nguời bệnh không đồng ý tham gia nghiên cưu, hay hồ so bệnh án không đầy đủ. Thời gian thu thập số liệu tì̀ tháng 1 /8 /2019 đến 30 /4 / 2020.

\subsection{Phương pháp nghiên cứu:}

2.2.1. Thiết kế nghiên cứu: Nghiên cưu mô tả hồi cúu và tiến cứu.

\subsubsection{Cõ̃ mẫu: Cõ mẫu thuận tiện.}

2.2.3. Phuơng pháp thu thập số liệu: Phỏng vấn trực tiếp đối tượng nghiên cứu trước và sau 
ghép tim về các thông tin chung, thông tin bệnh lý, chất lượng cuộc sống theo bộ câu hỏi SF36 (phiên bản 1.0) - gồm 8 yếu tố về sức khỏe: hoạt động thể lực, các hạn chế do sức khỏe thể lực, các hạn chế do dễ xúc động, sinh lực, sức khỏe tinh thần, hoạt động xã hội, cảm giác đau, sức khỏe chung. Một số thông tin về tiền sử cũng như các thông tin về bệnh lý, phẫu thuật của đối tượng nghiên cứu được trích lấy từ bệnh án.

\subsubsection{Phương pháp phân tích số liệu: Số} liệu định lượng sau khi thu thập được xử lý, nhập vào máy tính với phần mềm Epi Data 3.1 và được xử lý bằng phần mềm SPSS 22.0 for Window cho các thông tin mô tả và phân tích thống kê. Áp dụng các phương pháp phân tích mô tả - tính tỉ lệ phần trăm, giá trị trung bình, độ lệch chuẩn. Sử dụng các thuật toán thống kê - mô tả tần suất, tỷ lệ cho các biến phân loại; mô tả trung bình (Mean) và độ lệch chuẩn $(\mathrm{SD})$ cho các biến liên tục có phân bố chuẩn; mô tả trung vị (Median) và khoảng phân vị cho các biến liên tục không phân bố chuẩn.

Điểm CLCS được đánh giá [30]:

\section{1. Đặc điểm người bệnh trước ghép tim}

- Đặc điểm dịch tễ học

Bảng 1. Phân bố tuổi bệnh nhân vào thời điểm ghép tim

\begin{tabular}{|c|c|c|}
\hline Nhóm tuổi (năm) & $\mathbf{n}$ & Tỉ lệ \% $\mathbf{~ ( n = 2 3 ) ~}$ \\
\hline$\leq 18$ & 3 & 13,0 \\
\hline $18-34$ & 2 & 8,7 \\
\hline $35-49$ & 10 & 43,5 \\
\hline $50-65$ & 8 & 34,8 \\
\hline
\end{tabular}

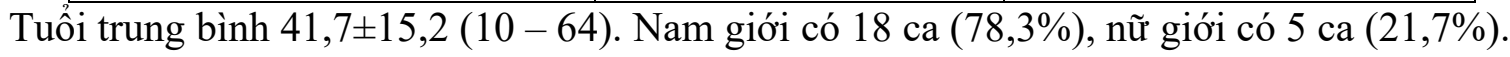

Phân bố bệnh nhân trước ghép theo nơi sinh sống: Nông thôn 11 ca (47,8\%); Thành thị 12 ca (52,2\%).

Phân bố bệnh nhân trước ghép theo trình độ học vấn: Tiểu học - Trung học cơ sở 2 ca (đang học -8,6\%); Phổ thông trung học $11 \mathrm{ca}(47,8 \%)$; Cao đẳng, Đại học $10 \mathrm{ca}(43,6 \%)$.

Bảng 2. Phân bố bệnh nhân trước ghép theo nghề nghiệp

\begin{tabular}{|l|c|c|}
\hline Nghề nghiệp & $\mathbf{n}$ & Tỉ lệ \% $\mathbf{~ ( n = ~ 2 3 ) ~}$ \\
\hline Cán bộ, viên chức & 6 & 26,1 \\
\hline Tự do & 5 & 21,7 \\
\hline Kinh doanh & 4 & 17,4 \\
\hline Hưu trí & 1 & 4,3 \\
\hline Làm ruộng, nông dân. & 4 & 17,4 \\
\hline Học sinh & 3 & 13,1 \\
\hline
\end{tabular}


Phân bố bệnh nhân trước ghép theo tình trạng hôn nhân gia đình: 19/23 trường hợp có gia đình riêng $(92,6 \%)$.

Các đặc điểm cá nhân nhập viện trước ghép về lối sống: 14/23 trường hợp không hút thuốc lá $(60,9 \%) ; 17 / 23$ trường hợp không uống rượu $(73,9 \%)$.

Chỉ số BMI bình thường chiếm 78,3\% (18 ca); thiếu cân $21,7 \%$ (5 ca); không có thừa cân.

Nhóm máu O chiếm 43,5\% (10 ca); máu B chiếm 30,4\% (7 ca); máu A chiếm 21,7\% (5 ca); và máu $\mathrm{AB}$ chiếm $4,3 \%(1 \mathrm{ca})$

- Tình trạng kinh tế, chi phí điều trị:

Tất cả người bệnh đều có Bảo hiểm y tế. Các chi phí ngoài bảo hiểm y tế được chi trả bởi bệnh nhân và gia đình họ (18 ca - 78,3\%); bởi họ hàng thân thích $(1 \mathrm{ca}-4,3 \%)$; bởi trợ giúp xã hội và họ hàng $(4 \mathrm{ca}-17,4 \%)$.

Phân bố bệnh nhân theo mức thu nhập gia đình thì hộ nghèo có 2 ca $(8,7 \%)$; còn lại ở mức trung bình $(52,2 \%)$ và khá giả $(39,1 \%)$.

- Một số đặc điểm bệnh lý:

Bảng 3. Phân bố theo bệnh tim chính dẫn đến suy tim

\begin{tabular}{|l|c|c|}
\hline Nguyên nhân suy tim & $\mathrm{n}$ & Tỷ lệ \% $(\mathrm{n}=23)$ \\
\hline Bệnh cơ tim giãn & 21 & 91,3 \\
\hline Bệnh động mạch vành & 2 & 8,7 \\
\hline
\end{tabular}

Bảng 4. Phân bố tình trạng ưu tiên trước ghép theo UNOS [7]; NYHA và Chức năng tim (EF)

\begin{tabular}{|l|l|c|c|}
\hline \multicolumn{2}{|c|}{ Chỉ số } & $n$ & Tỷ lệ \% $(\mathrm{n}=23)$ \\
\hline \multirow{4}{*}{ Uuu tiên theo UNOS } & Loại Ia & 9 & 39,3 \\
\cline { 2 - 4 } & Loại Ib & 11 & 47,8 \\
\cline { 2 - 4 } & Loại II & 03 & 13,0 \\
\hline \multirow{4}{*}{ NYHA } & III & 6 & 26,1 \\
\cline { 2 - 4 } & III-IV & 4 & 17,4 \\
\cline { 2 - 4 } & IV & 13 & 56,5 \\
\hline \multirow{4}{*}{ EF (\%) } & $31-35$ & 5 & 21,7 \\
\cline { 2 - 4 } & $21-30$ & 13 & 56,6 \\
\cline { 2 - 4 } & $\leq 20$ & 5 & 21,7 \\
\hline
\end{tabular}

Bảng 5. Phân bố theo thời gian phát hiện bệnh và số lần nằm viện

\begin{tabular}{|l|c|c|c|}
\hline \multicolumn{2}{|c|}{ Chỉ số } & $\mathrm{n}$ & Tỉ lệ \% $(\mathrm{n}=23)$ \\
\hline \multirow{3}{*}{$\begin{array}{c}\text { Thời gian phát } \\
\text { hiện bệnh (tháng) }\end{array}$} & $\leq 6$ & 5 & 21,7 \\
\cline { 2 - 4 } & $7-12$ & 4 & 17,4 \\
\cline { 2 - 4 } & $13-36$ & 8 & 34,8 \\
\hline \multirow{2}{*}{ Số lần nằm viện } & $>36$ & 6 & 26,1 \\
\cline { 2 - 4 } & $<3$ & 0 & 0 \\
\hline
\end{tabular}

Phân bố theo các bệnh lý phối hợp: viêm (loét) dạ dày 2 ca $(8,7 \%)$; suy thận 2 ca $(8,7 \%)$; xơ gan tim $4 \mathrm{ca}(17,4 \%)$; tiểu đường và Gout mỗi loại $1 \mathrm{ca}(4,3 \%)$. 


\subsection{Chất lượng cuộc sống người bệnh sau ghép tim:}

\section{- Đánh giá chung:}

100\% người bệnh trả lời họ được sự hỗ trợ tốt từ nhân viên y tế gia đình và xã hội sau ghép.

Bảng 5. Thời gian sống sau ghép cứu tính đến thời điểm nghiên cứu

\begin{tabular}{|l|l|c|}
\hline \multicolumn{1}{|c|}{ Thời gian sống } & $\mathrm{n}$ & Tỉ lệ \% $(\mathrm{n}=23)$ \\
\hline $6-12$ tháng & 5 & 21.7 \\
\hline 13 - 36 tháng & 9 & 39.1 \\
\hline 37 - 60 tháng & 5 & 21.7 \\
\hline$\geq 60$ tháng & 4 & 17.4 \\
\hline
\end{tabular}

Bảng 6. Nghề nghiệp bệnh nhân quay lại làm việc sau xuất viện

\begin{tabular}{|l|c|c|}
\hline Nghề nghiệp & $\mathrm{n}$ & Tỉ lệ \% $(\mathrm{n}=23)$ \\
\hline Cán bộ, viên chức & 6 & 26,1 \\
\hline Không tham gia lao động & 3 & 13,0 \\
\hline Kinh doanh & 6 & 26,1 \\
\hline Hưu trí & 1 & 4,3 \\
\hline Làm ruộng, nông dân. & 4 & 17,5 \\
\hline Học sinh & 3 & 13,0 \\
\hline
\end{tabular}

Nhận xét: phần lớn người bệnh (87\%) người bệnh quay trở lại làm việc mà trước khi mắc bệnh họ đã làm. Cán bộ, viên chức làm công việc văn phòng đều đi làm việc lại bình thường sau 3 tuần xuất viện. Người bệnh tham gia công việc kinh doanh và học sinh, làm nông nghiệp công việc mức độ nhẹ cũng quay lại công việc trong vòng 2-3 tháng sau ra viện. Có 03 bệnh nhân không tham gia lao động do bệnh nhân và gia đình của họ không mong muốn tiếp tục đi làm.

Bảng 7. Thời gian người bệnh ghép tim trở lại lao động làm việc

\begin{tabular}{|l|c|c|}
\hline Thời gian sau ra viện & $\mathrm{n}$ & Tỉ lệ \% $(\mathrm{n}=20)$ \\
\hline 3 tuần & 7 & 35,0 \\
\hline 2 tháng & 11 & 55,0 \\
\hline 3 tháng & 2 & 10,0 \\
\hline
\end{tabular}

Lối sống của bệnh nhân sau ghép: có sự thay đổi nhiều, những bệnh nhân có hút thuốc và uống rượu bia trước ghép đã bỏ hẳn; và tình trạng khối cơ thể được kiểm soát: không béo phì và tình trạng cân nặng đều cải thiện sau ghép với BMI bình thường chiếm $87 \%$ (20 ca) và BMI hơi thấp 13\% (3 ca).

- Điểm CLCS đo lường bằng bộ công cu SF-36: 
Bảng 8. Điểm CLCS của người bệnh sau ghép tim theo các lĩnh vực

\begin{tabular}{|l|c|c|c|c|c|}
\hline \multicolumn{1}{|c|}{ Lĩnh vực sức khỏe } & $\mathrm{n}$ & $\mathrm{TB}$ & $\mathrm{Min}$ & $\mathrm{Max}$ & $\mathrm{SD}$ \\
\hline Hoạt động về thể chất & 23 & 86,0 & 65 & 100 & 9,8 \\
\hline Sự giới hạn do vai trò sức khỏe thể chất & 23 & 84,5 & 35 & 100 & $1, .2$ \\
\hline Sự đau đớn & 23 & 92,1 & 55,0 & 100 & 12,0 \\
\hline Sự giới hạn do vai trò sức khỏe tinh thần & 23 & 85,1 & 33,3 & 100 & 3,4 \\
\hline Năng lượng sống và sự mệt mỏi & 23 & 85,9 & 65,0 & 100 & 2,2 \\
\hline Trạng thái tâm lý & 23 & 84,0 & 56,0 & 95 & 2,2 \\
\hline Chức năng xã hội & 23 & 79,1 & 50,0 & 100 & 2,8 \\
\hline Hoạt động sức khỏe chung & 23 & 82,3 & 50,0 & 95 & 10,0 \\
\hline
\end{tabular}

Bảng 9. Điểm CLCS của người bệnh sau ghép tim chung

\begin{tabular}{|l|c|c|c|c|c|}
\hline \multicolumn{1}{|c|}{ Lĩnh vực sức khỏe } & $\mathrm{n}$ & $\mathrm{TB}$ & $\mathrm{Min}$ & $\mathrm{Max}$ & $\mathrm{SD}$ \\
\hline Chất lượng sống tinh thần & 23 & 83,5 & 65,5 & 98,0 & 8,7 \\
\hline Chất lượng sống thể chất & 23 & 86,3 & 57,5 & 97,5 & 9,5 \\
\hline Chất lượng sống chung & 23 & 84,9 & 61,5 & 97,8 & 8,8 \\
\hline
\end{tabular}

\section{BÀN LUẬN}

4.1. Đặc điểm người bệnh ghép tim tù̀ người cho đa tạng chết não:

Người bệnh có chỉ định ghép tim chủ yếu mắc các bệnh gây suy tim mạn tính, như các bệnh cơ tim giãn, viêm cơ tim, cơ tim hạn chế, mạch vành... Mặc dù có những tiến bộ trong điều trị kéo dài thời gian sống, suy tim mạn tính vẫn là nguyên nhân chính gây tử vong ở những người mắc bệnh tim mạch [12]. Suy tim có liên quan đến gánh nặng các triệu chứng tồi tệ, nhập viện thường xuyên và tỷ lệ tử vong cao. Tỷ lệ mắc suy tim mạn tăng theo tuổi, và tiên lượng tương tự như tỷ lệ tử vong trong các bệnh lý ung thư ác tính nhất định [13]. Dữ liệu từ Cơ quan quản lý ung thư khu vực West Midlands ở Anh cho thấy tỷ lệ sống sót sau 1 năm của bệnh nhân suy tim mạn tồi tệ hơn so với bệnh nhân mắc ung thư vú, tuyến tiền liệt hoặc bàng quang[14].
Suy tim có triệu chứng ảnh hưởng tiêu cực đến CLCS của các đối tượng do hạn chế các lĩnh vực hoạt động và xã hội khác nhau. Những người bị suy tim thường gặp phải tình trạng đau khổ về thể chất, chức năng và cảm xúc ở mức độ cao và chất lượng cuộc sống liên quan đến sức khỏe của họ không thể được bình thường ngay cả khi được điều trị tối ưu [15-16]. CLCS của bệnh nhân bị suy tim và bạn tình của họ rất kém so với: (i) những người đồng lứa tuổi của họ trong dân số nói chung; (ii) bệnh nhân mắc các bệnh mãn tính khác. Hơn nữa, trầm cảm là yếu tố quyết định mạnh mẽ đến CLCS của bệnh nhân suy tim mạn [17]. Nó đã được chứng minh rằng các bệnh nhân nam phàn nàn về sự mệt mỏi đáng kể, thiếu năng lượng và thái độ cam chịu [18] . Ngược lại, phụ nữ được đặc trưng bởi sự nhận thức tăng lên về tất cả các triệu chứng tiêu cực của suy tim mạn: họ mất niềm tin vào bản thân, và cảm thấy lo lắng tăng cao [19]. Những thái độ này làm tăng thêm sự phụ thuộc vào môi trường xung quanh và ảnh 
hưởng tiêu cực đến cuộc sống gia đình [20]. Trạng thái tâm lý của các đối tượng làm người bệnh nhập viện thường xuyên và kéo dài hơn, mà không hẳn do các triệu chứng của suy tim mạn

Trong những năm gần đây, sự quan tâm đã tập trung hơn vào CLCS của bệnh nhân suy tim mạn, dần trở thành điểm tiêu điểm quan trọng trong việc đánh giá hiệu quả của các lựa chọn điều trị khác nhau. Tuy nhiên, khi sử dụng khái niệm CLCS, nên lưu ý rằng nó không tương đương với tình trạng sức khỏe. Tình trạng sức khỏe hiện tại là một trong những yếu tố quyết định của CLCS, nhưng trên thực tế, đó là một khái niệm được sử dụng để chỉ xem xét một sự hiểu biết lâm sàng về sức khỏe. Bác sĩ quan tâm trước tiên về những thay đổi của các thông số sinh hóa và sinh lý trong quá trình điều trị. Tuy nhiên, bệnh nhân quan tâm nhiều hơn đến việc giảm bớt các triệu chứng, cải thiện chức năng hàng ngày và hoàn thành vai trò xã hội của họ. Đối với bệnh nhân, CLCS có thể quan trọng như tuổi thọ (ví dụ, các triệu chứng và tác động của bệnh tật của họ đối với chức năng xã hội, cảm xúc và nghề nghiệp) [21].

CLCS cũng là một chỉ số tiên lượng có giá trị. Đối với những bệnh nhân thuộc cùng nhóm suy tim mạn, những người có CLCS thấp được đặc trưng bởi nguy cơ nhập viện cao hơn đáng kể liên quan đến bệnh tiềm ẩn của họ, bao gồm nguy cơ tử vong cao hơn [22]. Rodriguez-Artalejo và cộng sự [23] nhận thấy rằng CLCS kém ở những bệnh nhân nhập viện vì suy tim được đo bằng các chỉ số sức khỏe: thể chất, tâm lý và sức khỏe chung có liên quan đến nguy cơ tái nhập viện và tử vong cao hơn $63 \%$ - 75\% trong vòng 6 tháng. Vì vậy, điều trị và chăm sóc không chỉ tập trung vào các triệu chứng thực thể của suy tim, mà còn tập trung vào phương pháp chăm sóc đa ngành liên quan đến tối ưu hóa trị liệu y tế, quản lý triệu chứng, giáo dục và các can thiệp để cải thiện CLCS.

Các triệu chứng chính của suy tim mạn làm hạn chế hoạt động hàng ngày và dẫn đến giảm
CLCS bao gồm: khó thở, mệt mỏi, yếu, hạn chế tập thể dục, buồn ngủ và phù ngoại biên. CLCS của bệnh nhân suy tim kém hơn đáng kể so với người khỏe mạnh hoặc thậm chí với những người mắc các bệnh mãn tính khác (ví dụ như tăng huyết áp, đái tháo đường, rung tâm nhĩ, đau thắt ngực, nhồi máu cơ tim mãn tính hoặc bệnh phổi tắc nghẽn mạn tính) [15-24]. Bệnh nhân suy tim mạn bị hạn chế tập thể dục, kiềm chế lối sống năng động. Tuy nhiên, các nghiên cứu đã cho thấy việc đánh giá các kết quả lâm sàng truyền thống (như mức độ hoạt động được bác sĩ đánh giá, phân suất tống máu thất trái, nồng độ NTproBNP trong máu) tương quan kém (nếu có) với mức độ hoạt động hàng ngày và sức khỏe chung của bệnh nhân suy tim [17], trong các giai đoạn tiến triển lâm sàng tương tự, chức năng và phản ứng khác nhau trong các tình huống cuộc sống hàng ngày khác nhau. CLCS có thể bị giảm ở bệnh nhân suy tim với phân suất tống máu thất trái $(\mathrm{EF})$ còn được bảo tồn hay đã giảm [25].

Trong 23 bệnh nhân được ghép tim trong nghiên cứu này có nhiều đặt điểm trước ghép giống với nhiều nghiên cứu khác trên đối tượng chờ ghép tim và đã được ghép tim trên thế giới trong nghiên cứu $\mathrm{M}$. Colvin-Adams và cs trong 10 năm từ 2003 đến 2013 [26]

Tuổi: tuổi trung bình trong nghiên cứu này là 41,7 $\pm 15,2$ (10-64) tuổi (trong đó có 3 bệnh nhân dưới 18 tuổi), trẻ hơn so với nghiên cứu của Heng-Hsin Tung (2009) tại Đài Loan 56 12,96 tuổi với 39,2\% trên 60 tuổi [27], nghiên cứu của P.H. Tseng (2010) là 47,68 tuổi [28], của Connie White-Williams và cs (2013) tại Anh là 53,8 tuổi [29], và của Laura (2011) tại Ý là $62 \pm 9,1$ tuổi [30]. Báo cáo của Taylor và cs (2006) của Hội ghép tim phổi thế giới thì tuổi trung bình là $51,7 \pm$ 9,2 ; và phân theo nhóm tuổi (bảng 1 ) thì tỷ lệ gần giống với báo cáo của Hội ghép tim phổi thế giới (tính đến $30 / 6 / 2017)$ lần lược là $\leq 18(11,9 \%)$, 18-34 (10,1\%), 35-49 (26\%), 50-64 (46,7\%) [31].

Giới tính: trong nghiên cứu nam giới 
chiếm 78,3\% tương đương hầu hết các báo cáo trên thế giới, như của L. Sirri và cs (2011) tại Ý là 79\% [30], của Heng-Hsin Tung (2011) tại Đài Loan là $75,2 \%$, của Connie White-Williams và cs (2013) tại Anh với 555 bệnh nhân được ghép tim là $78 \%$, và của Hội ghép tim phổi thế giới nam 2017 là $72 \%$ [31].

Trình độ họ vấn: trong nghiên cứu có $43,6 \%$ là cao đẳng - đại học trở lên, 47,8 \% là trung phổ thông, và $8.6 \%$ là tiểu học và trung học cơ sở; trong nghiên cứu của Heng-Hsin Tung (2011) tại Đài Loan thì tỷ lệ này lần lượt là $25,5 \%, 35,3 \%$ và $39,2 \%$. Trình độ học vấn cao hơn là điều kiện thuận lợi cho giáo dục sức khỏe và tuân thủ điều trị sau ghép.

Tình trạng tài chính: trong nghiên cứu, hoàn cảnh kinh tế khá 39,1\%, trung bình 52,2\% và thấp là $8,7 \%$ - tất cả đều có bảo hiểm $\mathrm{y}$ tế. Trong nghiên cứu của Heng-Hsin Tung (2011) tại Đài Loan thì tỷ lệ này lần lượt là $14,4 \%, 77,1 \%$ và $17,1 \%$. Điều kiện kinh tế tốt và và có bảo hiểm y tế cũng là một vấn đề thuận lợi cho chăm sóc và nâng cao chất lượng cuộc sống sau ghép.

Tình trạng hôn nhân: trong nghiên cứu có $82,6 \%$ bệnh nhân đã có gia đình và $100 \%$ là sống cùng gia đình, so với các nghiên cứu Fulvio Bergamo Trevizan và cs (2017) tại Brazil là 70\% [32], của Heng-Hsin Tung và cs tại Đài Loan là $84,3 \%$; tuy nhiên thì bệnh nhân ở các nghiên cứu khác nhận sự hỗ trợ về tài chính từ gia đình, người thân không như trong nghiên cứu này; ví dụ như báo cáo của Heng-Hsin Tung và cs tại Đài Loan có $60,1 \%$ bệnh nhân phải tự lo vấn đề tài chính cho bản thân có $7,8 \%$ bệnh nhân sống độc thân sau ghép tim, trong khi đó trong nghiên cứu này có 4 bệnh nhân $(17,4 \%)$ được phẫu thuật nhờ hỗ trợ tích cực tài chính từ cộng đồng và $100 \%$ bệnh nhân được sự hỗ trợ từ gia đình trước và sau ghép tim.

Nhóm máu: trong báo cáo tổ chức điều phối ghép tạng Mỹ 10 năm (2000-2100) với 28.283 bệnh nhân chờ ghép tim thì nhóm máu $O$ chiếm 44\%, nhóm A chiếm 39\%, nhóm B chiếm 13\% và nhóm $A B$ chiếm 4\%; và theo Hiệp hội ghép tim phổi thế giới 2017: tỷ lệ bệnh nhân được ghép có nhóm máu $O$ là 39,7\%, nhóm máu A là 40,6\%, nhóm máu $B$ là $13,7 \%$, và nhóm $A B$ là $6,0 \%$. Nhu vậy có hơi chênh với kết quả của nghiên cưu này về vị trí thứ 2 và 3 của nhóm máu $B$ và $A$.

Bệnh tim trước ghép: trong nghiên cứu có $98,3 \%$ bệnh nhân mắc bệnh cơ tìm giãn và $8,7 \%$ bệnh nhân suy tim do thiếu máu, gần tương đồng với nghiên cứu Heng-Hsin Tung và cs tại Đài Loan có lần lược là $84,3 \%$ bệnh cơ tim giãn và $14,4 \%$ bệnh nhân suy tim thiếu máu, tuy nhiên khác với Kovacevic-Preradovic (2009) tại Canada - trong 253 bệnh nhân ghép tim có 42\% bệnh cơ tim giãn và $39 \%$ bệnh suy tim thiếu máu [33], Antonella Galeone và cs (2014) tại Pháp trên nhóm 131 bệnh nhân sống trên 20 năm sau ghép tim có $57 \%$ bệnh nhân chẩn đoán giãn cơ tim trước ghép và $24 \%$ bệnh suy tim thiếu máu, Theo báo cáo của Hội ghép tim phổi thế giới năm 2009 thì tỷ lệ bệnh cơ tim không thiếu máu $53 \%$ và suy tim thiếu máu là 38\% [34].

Mức độ nặng- theo mức độ nhóm ưu tiên ghép của UNOS: trong nghiên cứu, nhóm 1 có 87,1\% -trong đó 39,3\% nhóm Ia (bệnh nhân ở tình trạng nặng nguy kịch trước ghép, phải nằm viện điều trị thuốc trợ tim liều cao liên tục hoặc phải hỗ trợ thở, thở máy) và 47,8\% nhóm Ib (bệnh nhân mức độ nặng vừa phải dùng thuốc trợ tim liều thấp, phải nhập viện hoặc điều trị tại nhà). Trong báo cáo của Steven A. Farmer (2013) tại Mỹ với 555 bệnh nhân ghép tim thì thuộc UNOS 1 có $61,8 \%$, và UNOS 2 có $38.2 \%$; nghiên cứu của K.L.Grady (1998) thì UNOS 1 là 46\% và UNOS 2 là $54 \%$. Như vậy bệnh nhân trong nghiên cứu chúng tôi có phần nặng hơn, có thể do vấn đề ghép tim ở Việt Nam chưa được nhận thức rõ, nhiều người bệnh cố điều trị bảo tồn - trong khi đó trên thế giới, chỉ định ghép tim được nhiều người dân đăng ký khi bệnh ở mức độ nhẹ hơn.

Mưc độ nặng-suy tim theo NYHA: có 56,5\% người bệnh suy tim NYHA IV và 17\% NYHA III- 
IV (triệu chứng cơ năng xảy ra ngay lúc nghĩ ngơi, chỉ một vận động thể lực nhẹ cũng gây triệu chứng cơ năng tăng), 26.1\% suy tim NYHA III (hạn chế nhiều vận động thể lực, mặc dù bệnh nhân khỏe khi nghỉ ngơi nhưng chỉ cần vận động nhẹ đã có triệu chứng cơ năng), trong khi nghiên cứu của K.L.Grady (1998) với 219 bệnh nhân được ghép tim, thì suy tim NYHA IV chiếm $44 \%$, và $52 \%$ NYHA III. Như vậy mức độ suy tim của chúng tôi cũng nặng hơn tương tự phân nhóm theo UNOS.

\subsection{Chất lượng cuộc sống người bệnh sau ghép:}

Cả 100\% người bệnh trong nghiên cứu này cho rằng họ được người nhà và nhân viên y tế hỗ trợ tốt về cả tinh thần và thể chất sau ghép. Chúng tôi chọn bệnh nhân để đánh giá vào thời điểm 6 tháng sau ghép tim về CLCS, vì theo nhiều nghiên cứu CLCS sau ghép tim, thì người bệnh sau ghép 6 tháng đã được ổn định về tình trạng phẫu thuật và có thể tái hòa nhập cộng đồng, trong nghiên cứu có 4 bệnh nhân sống trên 5 năm, 9 bệnh nhân sống trên 3 năm từ ngày ghép tim. Trong nghiên cứu của K.L.Grady à cs (1998) [35] với 219 bệnh nhân 6 tháng sau ghép tim thì CLCS sau khi được ghép tim 6 tháng thay đổi độ rõ rệt so với người bệnh trước khi ghép. Những khác biệt về chất lượng cuộc sống là trong các lĩnh vực sau: chức năng thể chất và nghề nghiệp, trạng thái tâm lý và tương tác xã hội.

Trong nghiên cứu này có hầu hết bệnh nhân (87\%) quay lại làm việc công việc mà trước khi tình trạng mắc bệnh trở nên nghiêm trọng, bao gồm: 26,1 \% làm kinh doanh, 26,1 làm cán bộ công - viên chức văn phòng, 17,5\% làm nông nghiệp và 13,0\% tiếp tục đi học; với thời gian quay lại công việc lần lược là sau ra viện 3 tuần $(35 \%), 2$ tháng $(55 \%)$ và 3 tháng $(10 \%)$; có $13 \%$ không tiếp tục làm việc mặc dù tình trạng sức khỏe ổn định do bản thân và gia đình của họ không muốn đi làm. Trong nghiên cứu của J.F. Delgado và CS (2015) [36] tại Tây Ban Nha - chỉ có $13,5 \%$ quay lại công việc sau 6 tháng và tăng lên 14,5\% sau 60 tháng được ghép tim. Một nghiên cứu khác tại Đài Loan của Tseng và cs., 2010 [28] thì 50 đối tượng ( $86 \%$ nam và $14 \%$ nữ) có độ tuổi 20-70 tuổi (trung bình 47,68), thời gian sau ghép tim từ 1 đến 4 năm, thì trong vòng 6 tháng có $10 \%$ nhân viên hành chính hoặc nhà hàng và cảnh sát đã tiếp tục công việc; sau 6 đến 12 tháng có $8 \%$ nhân viên hành chính, kiểm soát chất lượng và nhân viên thiết kế và lập kế hoạch đã tiếp tục công việc; sau 12 tháng có $14 \%$ các giáo viên, nhân viên bảo hiểm, quản lý, kỹ sư tin học và thợ sắt đã tiếp tục được công việc .

Thay đổi lối sống nguời bệnh sau ghép: trước ghép tim có $39,1 \%$ bệnh nhân còn hút thuốc và $26,1 \%$ có uống rượu; tuy nhiên sau ghép đã thay đổi hoàn toàn - không có bệnh nhân tiếp tục hút thuốc lá và uống rượu; đây là kết quả tác động tích cực của nhân viên y tế và người nhà bệnh nhân. Trong một báo cáo tổng quan hệ thống của Patrick Hofmann và cs (2018) [37] dựa trên 15 nghiên cứu từ 1998 đến 2015 trên bệnh nhân sau ghép tim hoặc phổi, có khoảng 12-33\% người bệnh tái hút thuốc lá sau ghép tim và là nguyên nhân gây tử vong lâu dài và các rối loạn sau ghép, tăng biến chứng ung thư.

Về chi số khối co thể sau ghép tim (BMI): trong số 23 bệnh nhân được ghép tim hầu hết bệnh nhân đều tăng cân sau ghép, tuy nhiên không có bệnh nhân mắc béo phì, tỷ lệ BMI ở mức bình thường là $87 \%$. Trong nghiên cứu của I.Milanniak và cs (2014) [38], có 32,54\% là bình thường, $46,74 \%$ là thừa cân và $18,34 \%$ là béo phì, không quan sát thấy sự khác biệt thống kê giữa $\mathrm{BMI}$ trước và sau khi ghép; thừa cân và béo phì sau ghép tim là phổ biến và phản ánh yếu tố nguy cơ mắc bệnh mạch máu cơ tim và các bệnh tim mạch khác cũng như hội chứng chuyển hóa ở những người nhận tim ghép.

Về điểm CLCS: hầu hết người bệnh trong nhóm nghiên cứu chúng tôi có tình trạng sức khỏe chung, sức khỏe tinh thần và thể chất đều ở mức khá và tốt, điểm sức khỏe chung trung bình 
$84,9 \pm 8.8$, trong đó sức khỏe khỏe tinh thần ở mức $83 \pm 8,7$, sức khỏe thể chất $86,3 \pm 9,5$. CLCS trong nghiên cứu chúng tôi cao hơn so với nghiên cứu của Phạm Văn Cường (2015) [39] trên 90 bệnh nhân suy tim mạn (30 van tim, 30 cao huyết áp và 30 bệnh mạch vành) - đã được điều trị tích cực, với sức khỏe chung trung bình $80,2 \pm 16,1$, trong đó sức khỏe khỏe tinh thần ở mức $83 \pm 8,7$, sức khỏe thể chất $74,3 \pm 12,3$. Trong nghiên cứu của Imran Saeed và cs (2008) sau 1 năm sức khỏe chung 57 ca ghép tim: sức khỏe tinh thần 72 và sức khỏe thể chất 65; còn trong nghiên cứu của Antonella Galeone và cs (2014) [40] tại pháp trên nhóm 131 bệnh nhân sống sau ghép tim 20 năm: điểm chất lượng cuộc sống chung là $69 \pm 16$ (trung vị 75), chất lượng sức khỏe tinh thần $68 \pm 20$ (trung vị 73), và sức khỏe thể chất $67 \pm 22$ (trung vị 72).

\section{KẾT LUẬN}

Nghiên cứu trên 23 bệnh nhân sau ghép tim từ 6 tháng đến 9 năm tại bệnh viện Hữu nghị Việt Đức, thấy có các đặc điểm dịch tễ học tương tự như các nghiên cứu khác, nhưng tình trạng người bệnh trước ghép nặng hơn, người bệnh nhận được hỗ trợ tốt hơn từ gia đình và nhân viên y tế trước và sau ghép, và điểm chất lượng cuộc sống là khá tốt. Ghép tim là một chỉ định tốt cho người bệnh suy tim giai đoạn cuối nhờ cải thiện được tốt chất lượng cuộc sống người bệnh sau phẫu thuật.

\section{TÀI LIỆU THAM KHẢO}

1. C. W. Yancy, M. Jessup, B. Bozkurt và cộng sự (2013). 2013 ACCF/AHA guideline for the management of heart failure: a report of the American College of Cardiology Foundation/American Heart Association Task Force on Practice Guidelines. J Am Coll Cardiol, 62 (16), e147-239.

2. A. S. S. Lois U. Nwakanma, John V. Conte, William A. Baumgartner (2008). Cardiac Surgery in the Adult., McGraw-Hill, New York.

3. A. J. M. a. W. D. P. Abhinav Humar ((2006)). Atlas of organ transplantation, Verlag London Limited 2006., Copyright Springer
4. A. S. F. M. Harwin (1995 ). Manual of Cardiac surgery. Second edition., Copyright 1995 by Spinger - Verlag New York, Inc.

5. K. K. Khush, W. S. Cherikh, D. C. Chambers và cộng sự (2018). The International Thoracic Organ Transplant Registry of the International Society for Heart and Lung Transplantation: Thirty-fifth Adult Heart Transplantation Report-2018; Focus Theme: Multiorgan Transplantation. $J$ Heart Lung Transplant, 37 (10), 1155-1168.

6. N. H. Ước (2018). Ghép tim Hiện tại và tương lai ở Việt Nam. Tim mạch học,

7. S. Beilby, R. Moss-Morris và L. Painter (2003). Quality of life before and after heart, lung and liver transplantation. The New Zealand Medical Journal (Online), 116 (1171), U381.

8. E. L. Christie JD, Aurora P, et al. (2009). The Registry of the International Society for Heart and Lung Transplantation: Twenty-sixth Official adult lung and heart-lung report 2009. J Heart Lung Transplant, 28: 1031.

9. B. F. W. J. K. E. M. RS; (1999). Outcomes research in surgery. World J Surg, 23,

10. W. JG. (1999). Outcomes research: What to measure. . World J Surg, 23,

11. A. G. F. R. (1994). A sociological perspective on health-related quality of life research. In: Albrecht GL Fitzpatrick R, eds. Advances in Medical Sociology, . Volume 5: Quality of Life in Health Care. Greenwich (CT: Jai Press Inc),

12. K. Dickstein, P. E. Vardas, A. Auricchio và cộng sự (2010). 2010 Focused Update of ESC Guidelines on device therapy in heart failure: an update of the 2008 ESC Guidelines for the diagnosis and treatment of acute and chronic heart failure and the 2007 ESC Guidelines for cardiac and resynchronization therapy. Developed with the special contribution of the Heart Failure Association and the European Heart Rhythm Association. Europace, 12 (11), 1526-1536. 
13. S. Stewart, K. MacIntyre, D. J. Hole và cộng sự (2001). More 'malignant' than cancer? Five-year survival following a first admission for heart failure. Eur J Heart Fail, 3 (3), 315-322.

14. J. G. Cleland, A. Cohen-Solal, J. C. Aguilar và cộng sự (2002). Management of heart failure in primary care (the IMPROVEMENT of Heart Failure Programme): an international survey. Lancet, 360 (9346), 1631-1639.

15. F. D. Hobbs, J. E. Kenkre, A. K. Roalfe và cộng sự (2002). Impact of heart failure and left ventricular systolic dysfunction on quality of life: a cross-sectional study comparing common chronic cardiac and medical disorders and a representative adult population. Eur Heart J, 23 (23), 1867-1876.

16. D. B. Bekelman, E. P. Havranek, D. M. Becker và cộng sự (2007). Symptoms, depression, and quality of life in patients with heart failure. J Card Fail, 13 (8), 643-648.

17. T. Muller-Tasch, F. Peters-Klimm, D. Schellberg và cộng sự (2007). Depression is a major determinant of quality of life in patients with chronic systolic heart failure in general practice. J Card Fail, 13 (10), 818-824.

18. J. Martensson, J. E. Karlsson và $B$. Fridlund (1997). Male patients with congestive heart failure and their conception of the life situation. J Adv Nurs, 25 (3), 579-586.

19. J. Martensson, J. E. Karlsson và B. Fridlund (1998). Female patients with congestive heart failure: how they conceive their life situation. J Adv Nurs, 28 (6), 1216-1224.

20. T. Jaarsma, P. Johansson, S. Agren và cộng sự (2010). Quality of life and symptoms of depression in advanced heart failure patients and their partners. Curr Opin Support Palliat Care, 4 (4), 233-237.

21. E. J. Stanek, M. B. Oates, W. F. McGhan và cộng sự (2000). Preferences for treatment outcomes in patients with heart failure: symptoms versus survival. J Card Fail, 6 (3), 225-232.
22. F. Alla, S. Briancon, F. Guillemin và cộng sự (2002). Self-rating of quality of life provides additional prognostic information in heart failure. Insights into the EPICAL study. Eur J Heart Fail, 4 (3), 337-343.

23. F. Rodriguez-Artalejo, P. GuallarCastillon, C. R. Pascual và cộng sự (2005). Healthrelated quality of life as a predictor of hospital readmission and death among patients with heart failure. Arch Intern Med, 165 (11), 1274-1279.

24. J. Juenger, D. Schellberg, S. Kraemer và cộng sự (2002). Health related quality of life in patients with congestive heart failure: comparison with other chronic diseases and relation to functional variables. Heart, 87 (3), 235-241.

25. T. Hoekstra, I. Lesman-Leegte, D. J. van Veldhuisen và cộng sự (2011). Quality of life is impaired similarly in heart failure patients with preserved and reduced ejection fraction. Eur $J$ Heart Fail, 13 (9), 1013-1018.

26. M. Colvin-Adams, J. M. Smith, B. M. Heubner và cộng sự (2015). OPTN/SRTR 2013 Annual Data Report: Heart. American Journal of Transplantation, 15 (S2), 1-28.

27. H. H. Tung, H. L. Chen, J. Wei và cộng sự (2011). Predictors of quality of life in hearttransplant recipients in Taiwan. Heart Lung, 40 (4), 320-330.

28. P. H. Tseng, S. S. Wang, C. L. Chang và cộng sự (2010). Job Resumption Status, Hindering Factors, and Interpersonal Relationship Within Post-Heart Transplant 1 to 4 Years as Perceived by Heart Transplant Recipients in Taiwan: A Between-Method Triangulation Study. Transplant Proc, 42 (10), 4247-4250.

29. C. White-Williams, K. L. Grady, S. Myers và cộng sự (2013). The relationships among satisfaction with social support, quality of life, and survival 5 to 10 years after heart transplantation. $J$ Cardiovasc Nurs, 28 (5), 407-416. 
30. L. Sirri, C. Magelli 1 và S. Grandi (2011). Predictors of perceived social support in long-term survivors of cardiac transplant: the role of psychological distress, quality of life, demographic characteristics and clinical course. Psychology and Health, 26 (1), 77-94.

31. T. I. S. FOR và H. A. L. TRANSPLANTATION (2017). Heart Transplant Demographics,https://ishltregistries.org/registries/q uarterlyDataReportResults.asp?organ $=$ HR\&rptTyp $\underline{\mathrm{e}=\mathrm{tx} \text { demo\&continent }=6}$

32. F. B. Trevizan, M. C. d. O. S. Miyazaki, Y. L. W. Silva và cộng sự (2017). Quality of Life, Depression, Anxiety and Coping Strategies after Heart Transplantation. Brazilian journal of cardiovascular surgery, 32 (3), 162-170.

33. T. Kovacevic-Preradovic, R. Jenni, E. N. Oechslin và cộng sự (2009). Isolated Left Ventricular Noncompaction as a Cause for Heart Failure and Heart Transplantation: A Single Center Experience. Cardiology, 112 (2), 158-164.

34. D. O. Taylor, J. Stehlik, L. B. Edwards và cộng sự (2009). Registry of the International Society for Heart and Lung Transplantation: Twenty-sixth Official Adult Heart Transplant Report-2009. J Heart Lung Transplant, 28 (10), 1007-1022.

35. K. L. Grady, A. Jalowiec và C. WhiteWilliams (1998). Quality of life 6 months after heart transplantation compared with indicators of illness severity before transplantation. American Journal of Critical Care, 7 (2), 106-116.

36. J. F. Delgado, L. Almenar, F. GonzálezVilchez và cộng sự (2015). Health-related quality of life, social support, and caregiver burden between six and 120 months after heart transplantation: a Spanish multicenter crosssectional study. Clin Transplant, 29 (9), 771-780.

37. P. Hofmann, C. Benden, M. Kohler và cộng sự (2018). Smoking resumption after heart or lung transplantation: a systematic review and suggestions for screening and management. 2018, 10 (7), 4609-4618.

38. I. Milaniak, P. Przybyłowski, K. Wierzbicki và cộng sự (2014). Posttransplantation body mass index in heart transplant recipients: determinants and consequences. Transplant Proc, 46 (8), 28442847.

39. H. A. T. Phạm Văn Cường, Huỳnh Văn Minh (2015). Đánh giá chất lượng cuộc sống theo bảng SF- 36 trước và sau điều trị tích cực bệnh nhân suy tim mạn

Truòng Đại Học Y Dược Huế.

40. A. Galeone, M. Kirsch, E. Barreda và cộng sự (2014). Clinical outcome and quality of life of patients surviving 20 years or longer after heart transplantation. Transplant International, 27 (6), 576-582. 